\title{
Using Student Perceptions of Collaborative Mapping to Facilitate Interdisciplinary Learning
}

\author{
Michele C. Everett, PhD \\ Lecturer, Interdisciplinary Studies \\ Coastal Carolina University
}

This article reports on a study that investigated student perceptions of the effectiveness of collaborative mapping as a teaching strategy to facilitate interdisciplinary learning. Forty-five students enrolled in an introduction to interdisciplinary studies course participated in the study. Qualitative data, collaborative maps and student evaluations were analyzed using content and thematic analysis. Findings provide new understandings about using student perceptions of learning experiences to inform classroom practice. These understandings have implications for addressing the increasing pressure to demonstrate teaching effectiveness and learning outcomes in higher education.

\section{Introduction}

The value of interdisciplinary learning in higher education is receiving increased attention and recognition (Boix Mansilla, 2005; Holley, 2009; Krometis, Clark, Gonzalez, \& Leslie, 2011; Lattuca, Voigt, \& Fath, 2004; Repko, 2012; Repko, Szostak, \& Buchberger, 2017; Szostak, 2007). This is due in part to understanding the essential role interdisciplinary thinking plays in resolving the serious and complex issues facing society today. Engaging in interdisciplinary work requires and develops a specific set of cognitive abilities and skills (Repko, 2012; Everett, 2016). Cognitive abilities include holistic, reflective, critical, problem-solving and creative thinking; skills developed include perspective-taking, collaboration and ethical consciousness (Repko et al., 2017). Importantly, these are the capabilities that are listed as top skills employers are looking for today (Brassler \& Dettmers, 2017; NACE, 2018).

Interdisciplinary learning involves making connections between two or more academic disciplines. The key cognitive task involved is integration. Repko (2012) defines interdisciplinary integration as, "The cognitive process of critically evaluating disciplinary insights and creating common ground among them to construct a more comprehensive understanding. The new understanding is the result of the integrative process" (p. 263). Integration is a challenging concept for students to understand and perform. It requires engaging in higher order thinking that goes beyond making comparisons, requiring students to critically analyze and synthesize information across disciplines (Carmichael \& LaPierre, 2014).

Identifying strategies that help students achieve learning outcomes is an essential part of teaching. As an instructor of interdisciplinary studies, this concept means employing teaching and learning strategies that facilitate the cognitive process of bringing together ideas from different disciplines and helping students understand and engage in the process of integration. Teaching strategies used in higher education to facilitate interdisciplinary learning include problem based and project-based learning (see Brassler \& Dettmers, 2017; Imafuku, Kataoka, Mayahara, \& Suzuki, 2014; $\mathrm{Ng}$, Yap, \& Hoh, 2011; Stentoft, 2017). Additional teaching methods for helping 
students make connections are mind maps and concept maps, terms that are frequently used interchangeably. While both mapping strategies serve as a graphic representation of ideas, the purpose and design of the two mapping methods are different. Mind maps were developed as a tool for organizing and brainstorming ideas. As shown in Figure 1, they have a radial design, one main idea in the center with themes branching outward, and typically include color, words and images (Buzan, 1994). Concept maps were developed for understanding science knowledge (Novak, 1990). Illustrated in Figure 2, they have a hierarchal design, drawn top-down, from general to more specific concepts (Duffill, 2013; Novak \& Cañas, 2008).

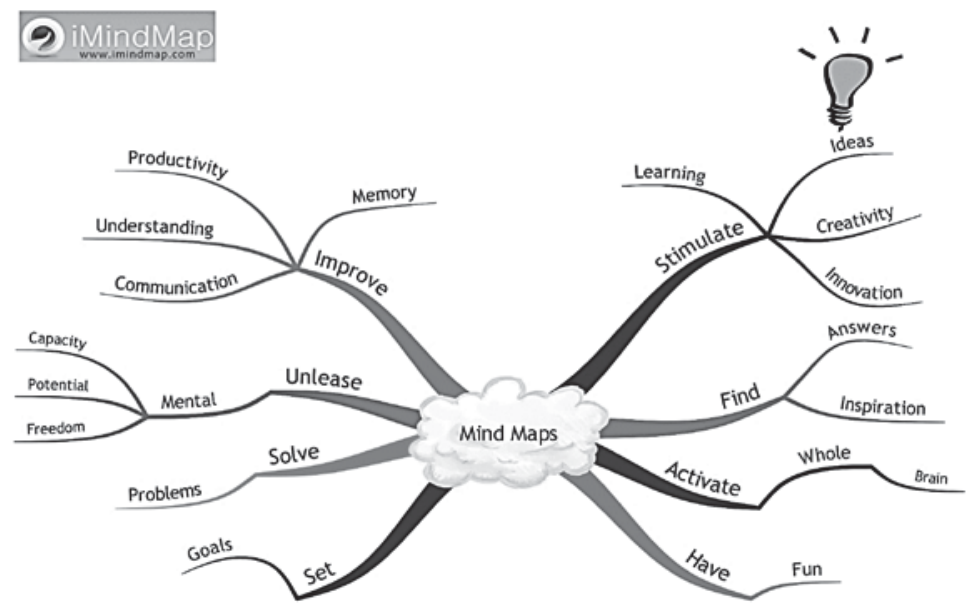

Figure 1. Mind Map ${ }^{1}$

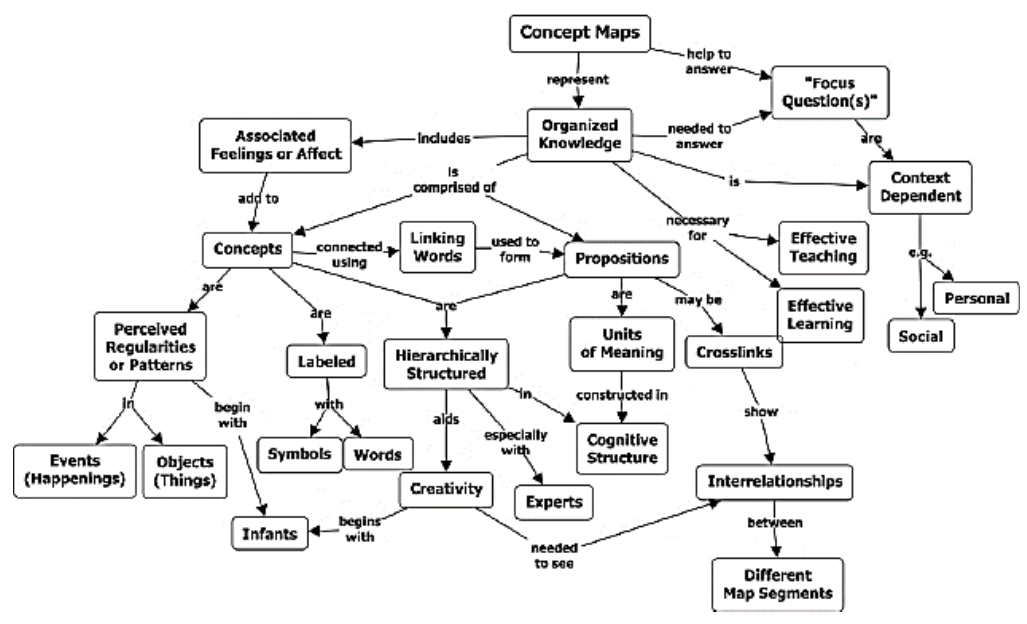

Figure 2. Concept Map (Novak \& Cañas, 2008)

${ }^{1}$ Mind Maps is a registered trademark of the Buzan Organisation Limited 1990, "www.tonybuzan.com." 
The literature on the use of mind and concept maps in higher education provides support for its effectiveness as a teaching strategy (Chiou, 2008; Hay, Kinchin, \& Lygo-Baker, 2008). To date, they have been used primarily in science education and as an individual student activity. Though not as commonly used, collaborative mapping, defined in this study as students creating mind maps and/or concept maps as a small group activity, has been found to enhance learning by encouraging the exchange of ideas (Kinchin \& Hay, 2005; Novak \& Cañas, 2008). In addition to being an instructional strategy, mind and concept maps have also been used as a tool for assessing learning (see Hay, Wells, \& Kinchin, 2008; Quinn, Mintzes, \& Laws, 2003).

Assessing the effectiveness of instructional methods used to meet learning objectives is a key factor in improving teaching practice. Although studies have been published on assessment of interdisciplinary learning (see Carmichael \& LaPierre, 2014; Mueller et al., 2014), the body of research is still in its infancy (You, Marshall, \& Delgado, 2018). While what has been reported provides insights on pedagogical principles for teaching interdisciplinary studies, including team teaching, learning communities, and discovery-based learning (Haynes, 2002; Klein, 2005), additional scholarship is needed to identify specific instructional strategies that promote an understanding of the process of integration. The purpose of this article is to report findings from a study that investigated the use of collaborative maps as a teaching method for facilitating interdisciplinary learning.

\section{Theoretical Framework}

This research is informed by the social constructivist perspective that learning is an active process shaped by prior knowledge and the social interactions and environment in which the learning takes place (Bruner, 1986; Vygotsky, 1978). Social constructivists view the role of the teacher as facilitator, providing students with a learner-centered, supportive and stimulating environment that promotes social interaction and discovery (Powell \& Kalina, 2009). Pedagogical applications of social constructivism in the context of higher education focus on small group cooperative and collaborative learning. Although there is considerable debate over the use and definition of the two terms, they have different theoretical underpinnings and expected outcomes. Cooperative learning is based on social interdependence theory (Johnson \& Johnson, 1999). It entails working together for a shared purpose. Collaborative learning stems from a social constructivism perspective. It is a teaching strategy that involves bringing together different ideas to "increase knowledge" or "deepen understanding" (Barkley, Cross, \& Major, 2014, p. 4). Barkley et al., (2014) identify three essential features of collaborative learning: (1) Planning - intentional design, (2) Process - co-laboring, all members contributing, and (3) Result - meaningful learning.

Positive outcomes from providing opportunities for students to interact with peers include encouraging dialogue and discussion that may lead to deeper levels of learning, promoting teamwork, and developing the ability to listen to diverse perspectives (Barkley et al., 2014). While there is a strong theoretical foundation for collaborative learning, there are challenges associated with using it in the classroom. Common complaints from students about group projects are group members who do not contribute their fair share of the work and interpersonal conflicts (Allen, 2016; 
Machemer \& Crawford, 2007). Strategies for addressing these issues include explaining the rationale for engaging in collaborative learning, establishing policies before the start of the project, and building in strategies for assessment at the individual and group level (Channon, Davis, Goode, \& May, 2017).

The theory of interdisciplinary studies as a way of understanding the world focuses on complexity and the nature of complex systems (Newell, 2001). Understanding complex systems requires a holistic and integrative approach to knowledge construction, one that promotes the

Collaborative mapping as a exchange of ideas and integration of insights pedagogical strategy brings across disciplines. The purpose of engaging in together theoretical principles of social constructivism and interdisciplinary learningactive engagement, creative and holistic thinking, integration of knowledge and collaboration. interdisciplinary studies is to gain a more comprehensive understanding of complex issues, which may lead to new viable solutions (Repko, 2012). Collaborative mapping as a pedagogical strategy brings together theoretical principles of social constructivism and interdisciplinary learning-active engagement, creative and holistic thinking, integration of knowledge and collaboration. The focus of this research is to investigate students' perceptions of its effectiveness as a teaching method for facilitating an understanding of interdisciplinary integration.

\section{Description of the Study}

This study was conducted during the 2017- 2018 fall and spring semesters at a medium-size, four-year public liberal arts institution located in southeastern US. Participants were 45 students enrolled in a 300-level three-credit Introduction to Interdisciplinary Studies (IDS) course. Although it is an upper-level course, it is open to all majors and academic levels. It fulfills an IDS major core requirement and serves as a cognate course for non-IDS majors.

The course is delivered face-to-face, two 75-minute class meetings per week for 15 weeks. The required textbook for the course is Repko, Szostak and Buchberger's (2017) Introduction to Interdisciplinary Studies. The overarching goal of the course is to provide students with theoretical and practical applications of interdisciplinary studies. Specific learning outcomes focus on students demonstrating an understanding of the process and result of engaging in the interdisciplinary research process (IRP) (Repko et al., 2017).

The purpose of the current study was to assess the effectiveness of using collaborative maps to facilitate student learning outcomes from an 8-week small group interdisciplinary project. The project involved researching a complex real-world problem for the purpose of designing a museum exhibit that presented an interdisciplinary understanding of the problem and solutions that emerge from the new understanding. Students self-selected groups and topics. Eleven groups participated in the study, 5 groups during the fall 2017 term, 6 groups in the spring 2018 term. Group size ranged from 3-5 students. The groups consisted of students from different academic interests and backgrounds. 
The first five weeks of the semester were spent covering the material presented in the course textbook. The group project was introduced during the sixth week of classes. Groups started the project by brainstorming complex real-world problems to use as the topic for their museum exhibit. After a topic was identified, students followed the steps in the IRP presented in the textbook to develop and design their museum exhibit. During the project, students worked on different assignments; some assignments were individual, other assignments were completed as a group. Key assignments included an annotated bibliography (individual), disciplinary insights table (group), and a written discussion of the interdisciplinary understanding of the problem (group). The final assignment was a written museum exhibit proposal and an oral presentation of the proposal (group).

In the initial stages of the project, students conducted research to understand the problem from relevant disciplinary perspectives, each student responsible for understanding the problem from a different discipline. During the later stages, students shared discipline-specific insights about the problem with their group members. At specific times during the 8-week project, students were instructed to produce maps. Before drawing the first map, the instructor provided an overview of mapping and showed students examples of mind and concept maps. In this study, because maps were used for brainstorming and to generate new knowledge, students were given the freedom to use a design that made the most sense to members of the group. After the teaching strategy was introduced, the instructor referred to both mapping strategies, mind and concept maps, as "mind maps" for the duration of the course. Each group produced a series of four maps: Map 1 - potentially relevant disciplines (collaborative), Map 2 - most relevant disciplines (collaborative), Map 3 discipline-specific map (individual), and Map 4 - "integration" map (collaborative).

\section{Data Generation and Analysis}

Data were generated from two sources: (1) 11 group collaborative integration maps, and (2) 42 individual student evaluations; due to absences, three students did not provide evaluation comments. The first data set, the collaborative integration maps (Map 4), provided a graphic representation of the relationships between insights from different disciplines. Before starting work on this map, students were instructed to find and show connections between insights, to identify interdisciplinary themes, and to provide a legend to help interpret their map. They had the choice of hand drawing their maps using the paper and drawing materials (markers / highlighters) provided or using their laptop computers. Students were given class time to work as a group to create their integration maps. A primary goal for the activity was for students to use these maps to write a discussion of the interdisciplinary understanding of the problem.

Student evaluations used to gain an understanding of student perceptions served as the second data set. After students completed their interdisciplinary discussion assignment, they provided a written evaluation of the collaborative mapping exercise. They were asked to reflect on the process of constructing the integration map and to assess its effectiveness in helping them understand the process and result of interdisciplinary integration. The prompt for the written evaluation was Do you feel the integration map helped you / your group construct an interdisciplinary 
understanding of the problem you're using for the museum exhibit project? If yes, in what ways did it help? If no, why not?

Qualitative content and thematic analysis (Patton, 2002) were employed to analyze the data. Analysis occurred in two stages: (1) collaborative integration maps, (2) student evaluations. The following steps were used to analyze graphic representations of the interdisciplinary integration process presented in the collaborative maps:

1. Categorizing maps by design: modified mind map, modified concept map, other

2. Viewing and re-viewing the maps to identify structure and layers

3. Viewing and re-viewing the maps to assess connections between disciplinary insights

4. Viewing and re-viewing the maps to identify and record interdisciplinary themes

Student evaluations were analyzed by:

1. Entering all comments on a MS Word document

2. Color-coding comments into three categories: effective, not effective, not sure

3. Placing comments under appropriate category headings

4. Reading and analyzing comments under each heading to identify patterns of repeated words and phrases

5. Using the "find" function to count frequency of repeated words

6. Organizing comments into initial sub-categories

7. Re-reading comments and revising sub-category headings

8. Reading comments under each sub-category to identify emergent themes Analysis of the two data sets served to meet the research aims to understand students' perceptions of the effectiveness of collaborative mapping as an instructional strategy.

\section{Findings}

The study's findings are presented in two sections: (1) analysis of visual representations of the interdisciplinary integration process and (2) analysis of evaluation comments to gain students' perceptions of using collaborative maps as an instructional strategy for facilitating interdisciplinary learning.

\section{Visual Representations}

Figures $3-7$ on p. 119 illustrate the variety of designs groups used to present the process of interdisciplinary integration. Many groups created modified mind maps using a radial design with the problem in the center, disciplines and disciplinary insights branching outward (e.g., Figures 3 and 4); one group designed their mind map from the outside in, with disciplinary insights radiating inward from interdisciplinary themes (Figure 5); one group produced a modified concept map using a hierarchical design (Figure 6); one group used a tree design (Figure 7). The structure of the maps also varied. While the relevant disciplines used to investigate the problem served as the main categories in seven maps (e.g., Figure 4), some groups used interdisciplinary 
themes (e.g., Figure 5); 1 group used "connections" "disagreements" and "new understandings" as the main categories on their map.

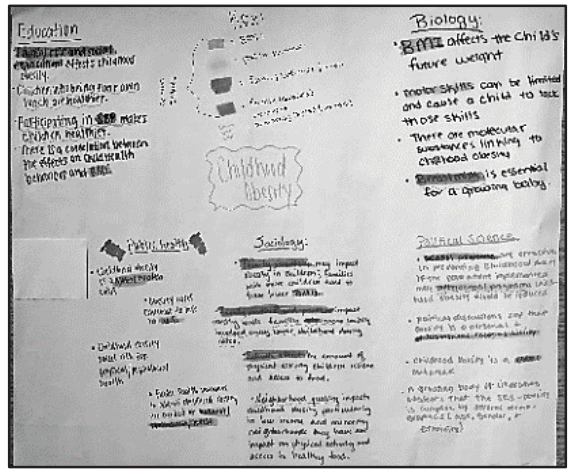

Figure 3. Collborative Map (F5)

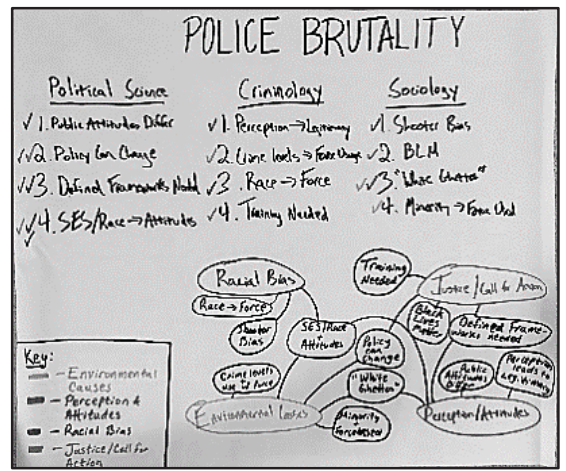

Figure 5. Collborative Map (S6)

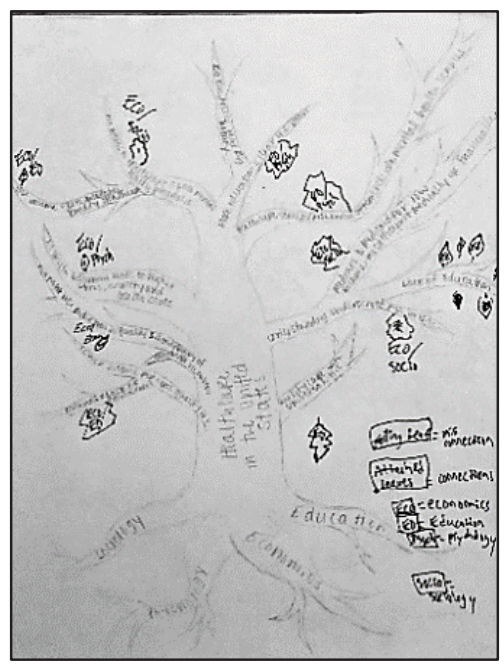

Figure 7. Collborative Map (F2)

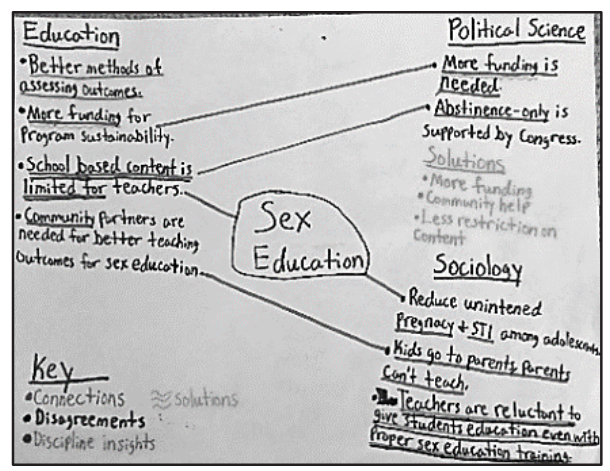

Figure 4. Collborative Map (S3)

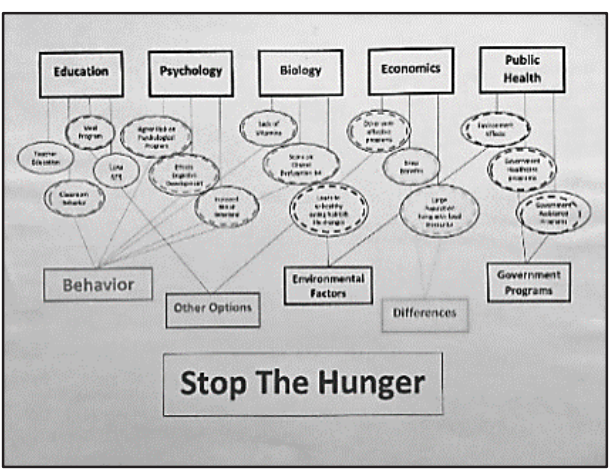

Figure 6. Collborative Map (F3)

Groups employed different approaches to show the connections between disciplinary insights. Four groups chose to use color coding (e.g., Figure 3); six groups used both color coding and lines to show commonalities and differences between insights (e.g., Figures 4 and 6); one group used branches and leaves (Figure 7). Concerning the legends used to explain maps, four groups used interdisciplinary themes (e.g., Figures 3 and 5), legends on four maps included similarities and differences between insights (e.g., Figure 4); two groups included "solutions" (Figures 3 and 4). Discipline names and "attached" and "falling" leaves were the descriptors provided on the tree map legend. The range of designs and ways of representing connections and themes suggests 
that students used the freedom they had to express the group's collective creativity and to personalize the meaning-making experience.

The collaborative maps were also analyzed to assess graphic representations of the steps involved in the interdisciplinary integration process: identifying conflicts and commonalities between insights across disciplines, finding common ground, and generating interdisciplinary themes. While all groups identified connections, the relationships between disciplinary insights were easier to identify on maps produced by certain groups. The number of connections and the number of disciplines connected to each theme also varied.

Table 1 presents the topic, the names of the disciplines each group used for the project, and the interdisciplinary themes identified. Analysis of the themes suggests that groups reached different levels of understanding the integrative process. For example, the map created by group S6 (Figure 5) presents a clear representation of the process of identifying connections between interdisciplinary insights and generating themes across all three disciplines, indicating a high level of interdisciplinary integration. In comparison, the map produced by group F2 (Figure 7), does not include interdisciplinary themes, and thus shows little evidence of interdisciplinary integration. Many factors could have influenced the difference in the degree of interdisciplinary integration demonstrated on the maps, including drawing ability, prior experience with mapping, degree of understanding the task and the integrative process, relationship with / seeking help from the instructor, level of engagement, motivation and interest in the topic, commitment to learning and project success, and group dynamics. It is worth noting that the groups that demonstrated a deeper level of interdisciplinary integration on their collaborative maps were also the groups that received the highest grades on their final project.

Table 1

Collaborative maps - topic, disciplines and interdisciplinary themes

\begin{tabular}{|c|c|c|c|}
\hline $\begin{array}{l}\text { Group } \\
\text { ID }\end{array}$ & Topic & Disciplines & $\begin{array}{l}\text { Interdisciplinary Themes } \\
\text { (Disciplines) }\end{array}$ \\
\hline F1 & $\begin{array}{l}\text { Climate } \\
\text { Change }\end{array}$ & $\begin{array}{l}\text { Biology (BIO) } \\
\text { Economics (ECO) } \\
\text { Sociology (SOC) } \\
\text { Environmental } \\
\text { Science (ES) } \\
\text { Political Science } \\
\text { (PS) }\end{array}$ & $\begin{array}{l}\text { - Poor water quality (BIO / ES) } \\
\text { - Human health \& livelihood (BIO / } \\
\text { SOC) } \\
\text { - Migration (BIO / SOC) } \\
\text { - Economic performance (BIO / } \\
\text { ECO / ES) } \\
\text { - Accelerated by pollutants (BIO / } \\
\text { PS / ES) } \\
\text { - Global topic (BIO / ECO / SOC / } \\
\text { ES / PS) }\end{array}$ \\
\hline F2 & $\begin{array}{l}\text { Health Care } \\
\text { in the US }\end{array}$ & $\begin{array}{l}\text { Economics (ECO) } \\
\text { Education (ED) } \\
\text { Sociology (SOC) } \\
\text { Psychology (PSY) }\end{array}$ & \\
\hline
\end{tabular}


Table 1 Continued

\begin{tabular}{|c|c|c|c|}
\hline $\begin{array}{l}\text { Group } \\
\text { ID }\end{array}$ & Topic & Disciplines & $\begin{array}{l}\text { Interdisciplinary Themes } \\
\text { (Disciplines) }\end{array}$ \\
\hline F3 & $\begin{array}{l}\text { Hunger in } \\
\text { the US }\end{array}$ & $\begin{array}{l}\text { Education (ED) } \\
\text { Psychology (PSY) } \\
\text { Biology (BIO) } \\
\text { Economics (ECO) } \\
\text { Public Health (PH) }\end{array}$ & $\begin{array}{l}\text { - Behavior (ED / PSY / BIO) } \\
\text { - Environmental factors (BIO / PH) } \\
\text { - Government programs (PH) }\end{array}$ \\
\hline F4 & $\begin{array}{l}\text { Marine } \\
\text { Plastic } \\
\text { Pollution }\end{array}$ & $\begin{array}{l}\text { Marine Biology } \\
(\mathrm{MB}) \\
\text { Environmental } \\
\text { Science (ES) } \\
\text { Economics (ECO) } \\
\text { Sociology (SOC) } \\
\text { Education (ED) }\end{array}$ & $\begin{array}{l}\text { - Behavior (SOC / EDU / ECO) } \\
\text { - Knowledge (SOC / MB / EDU / } \\
\text { ECO / ES) } \\
\text { - Policy (SOC / MB / ECO / ES) }\end{array}$ \\
\hline F5 & $\begin{array}{l}\text { Childhood } \\
\text { Obesity }\end{array}$ & $\begin{array}{l}\text { Education (ED) } \\
\text { Biology (BIO) } \\
\text { Public Health (PH) } \\
\text { Sociology (SOC) } \\
\text { Political Science } \\
\text { (PS) }\end{array}$ & $\begin{array}{l}\text { - BMIs (ED / SOC / BIO) } \\
\text { - Physical promotion (BIO / PH / } \\
\text { SOC / PS) } \\
\text { - Family / school (ED / SOC / BIO / } \\
\text { PS) } \\
\text { - Global awareness (ED / PH / PS) }\end{array}$ \\
\hline S1 & $\begin{array}{l}\text { Homeless } \\
\text { Veterans }\end{array}$ & $\begin{array}{l}\text { Political Science } \\
\text { (PS) } \\
\text { Public Health (PH) } \\
\text { Education (EDU) } \\
\text { Psychology (PSY) } \\
\text { Economics (ECO) }\end{array}$ & $\begin{array}{l}\text { - Community support (PH / PSY) } \\
\text { - Funding (PH / ECO / EDU) } \\
\text { - Policy (PS / PH) } \\
\text { - Programs (PH / EDU) }\end{array}$ \\
\hline S2 & $\begin{array}{l}\text { Legalization } \\
\text { of } \\
\text { Marijuana }\end{array}$ & $\begin{array}{l}\text { Economics (ECO) } \\
\text { Law (LAW) } \\
\text { Psychology (PSY) } \\
\text { Public Health (PH) }\end{array}$ & $\begin{array}{l}\text { - Illicit use (ECO / LAW / PH) } \\
\text { - Effects (ECO / LAW / PSY / PH) }\end{array}$ \\
\hline S3 & $\begin{array}{l}\text { Sex } \\
\text { Education }\end{array}$ & $\begin{array}{l}\text { Education (ED) } \\
\text { Political Science } \\
\text { (PS) } \\
\text { Sociology (SOC) }\end{array}$ & $\begin{array}{l}\text { - Funding (ED / SOC / PS) } \\
\text { - Community support (ED / SOC / } \\
\text { PS) } \\
\text { - Content (ED / SOC / PS) }\end{array}$ \\
\hline $\mathrm{S} 4$ & $\begin{array}{l}\text { Climate } \\
\text { Change }\end{array}$ & $\begin{array}{l}\text { Environmental Law } \\
(\text { EL) } \\
\text { International } \\
\text { Relations (IR) } \\
\text { Economics (ECO) } \\
\text { Biology (BIO) }\end{array}$ & $\begin{array}{l}\text { - Law \& policy (EL / IR / ECO / } \\
\text { BIO) } \\
\text { - Environmental health (EL / IR / } \\
\text { ECO / BIO) } \\
\text { - Global impacts (EL / IR / ECO / } \\
\text { BIO) } \\
\text { - Economic impacts (EL / IR / ECO } \\
\text { / BIO) }\end{array}$ \\
\hline
\end{tabular}


Table 1 Continued

\begin{tabular}{clll}
\hline $\begin{array}{c}\text { Group } \\
\text { ID }\end{array}$ & Topic & Disciplines & $\begin{array}{l}\text { Interdisciplinary Themes } \\
\text { (Disciplines) }\end{array}$ \\
\hline S5 & Women's & Religious Studies & - Individual vs societal / religious \\
& Choice & $\begin{array}{l}\text { (RS) } \\
\text { Psychology (PSY) } \\
\text { Women Studies }\end{array}$ & - Consequences (RS / PSY / WGS) \\
& & (WGS) & \\
& & Political Science & - Environmental causes (PS / CRIM \\
S6 & Police & / PS) & - Perceptions \& attitudes (PS / \\
& Brutality & Criminology & CRIM / SOC) \\
& & (CRIM) & - Racial bias (PS / CRIM / SOC) \\
& & Sociology (SOC) & - Justice / call for action (PS / CRIM \\
& & & / SOC) \\
\hline
\end{tabular}

\section{Perceptions}

Evaluation comments were analyzed to gain students' perceptions of using collaborative mind maps to facilitate an understanding of interdisciplinary integration. The vast majority of students expressed the view that the integration mind map helped them construct an interdisciplinary understanding of the problem; 38 students $(90.5 \%)$ found it useful, 3 students (7.1\%) did not find it useful, and 1 student (2.4\%) was not sure if it helped facilitate an understanding of the integration process.

The reasons students provided for its effectiveness as a teaching and learning strategy focused on the benefits derived from the visual aspect of the activity, as a different way to see, clarify and organize information.

- $\quad$ The mind map did help me have a physical representation of what the connections look like. I tend to be more of a visual learner. So I needed that physical representation to put it all together.

- I like using mind maps because it lays out ideas visually. I am a visual learner so I understand the process better when it comes to an IDS understanding of a complex real-world problem.

- Absolutely. Personally, my thoughts were scattered until I saw the completed mind-map.

- Being a visual learner, it especially helped me see everything more clearly and more organized and laid out.

Additional benefits identified include facilitating the steps in the integration process: finding connections between disciplinary insights, creating common ground, integrating insights, and constructing an interdisciplinary understanding of the problem.

- By constructing a mind map, the connections between the disciplinary insights were much more visible.

- Made it easy to pick out connections, conflict, themes and create common ground. 
- It helped by providing a visual of our thoughts together making it easier to integrate.

- Seeing all the insights, being able to highlight and physically make connections was very helpful in forming an interdisciplinary understanding.

- The integration mind-map helped me construct and interdisciplinary understanding of the problem because it helped me to see key themes and solutions to the problem.

- I think the mind maps are a great idea for helping students understand the process required to construct an interdisciplinary understanding of a complex real-world problem.

- It helps people ... to see how other disciplines connect with others and it allows them to gain a better understanding as to why an interdisciplinary perspective can accomplish more than just a single discipline on its own.

In addition to facilitating the process of interdisciplinary integration, the mapping activity provided students with opportunities for creative and holistic thinking.

- Yes, much like IDS this is a different way of looking at things. ... Having something like this may help someone think outside the box, stimulate other parts of the brain as it did for me.

- Mind maps enable us to see the "pathways" to new ideas \& insights that come from different disciplines. "All roads lead to a destination" and that destination is a new solution to a real world problem.

- Yes, I like thinking outside the box \& "drawing" our perspectives \& disciplines helped me to visualize \& understand the concept better.

- Mind maps really do allow you to physically see your process of integrating disciplines to connect them and "see the bigger picture."

- Mind maps are a creative visual way to see what disciplines can bring to solve a complex problem. It also helps when students need ideas.

Student comments also highlight the active and collaborative nature of the activity:

- Yes, it completely helped our group who happened to be learners who were better with hands on and visual things. We got the chance to see our ideas come to life right in front of our eyes which truly helped us.

- $\quad$ The mind map helped by putting our thoughts on paper and playing around with different designs. The group made four common themes / connections between insights. The group had a great grasp on the multidisciplinary process. We also had a good idea of the interdisciplinary process, which led to a better understanding of the problem.

- Each person had a different opinion which allowed us to have a discussion.

- I believe that the integration mind-map was very helpful because it gave us a nice visual and brought ideas that we had in our heads as a group.

- Yes, the integration mind map helped me individually and as a group to have a clear understanding of our topic / project as a whole. 
- Yes, because it organizes everyone's ideas together to come up with a better understanding.

Some students who found the instructional strategy useful, reported that it was confusing at first.

- Mind maps were okay, they can get a little confusing if you don't know how to follow, but if you personalized it like my group did it was helpful. The view that mind maps can be confusing and preferences for other learning strategies were the reasons students provided for why collaborative mapping did not facilitate interdisciplinary learning.

- I believe charts are a better visual representation to understand the process, like the insights table or flow chart. The mind map gets too confusing sometimes to follow.

- Mind maps were rather confusing for me. I prefer things that are organized and the mind maps tended to be all over the place.

- The mind map to me personally seemed a little crazy, and hard to understand, color coding works better for me and helps me visually see connections between insights much better.

The student who was unsure about the teaching strategy's effectiveness, made a distinction between it helping to identify insights shared across disciplines and helping "develop a new interdisciplinary understanding."

\section{Discussion \& Implications}

This study illustrates how student perceptions can be used to inform classroom practice. The findings reveal features of collaborative mapping that contributed to its effectiveness as a teaching strategy and the learning outcomes from the activity. They also provide suggestions for improvement.

\section{Effective Features}

The feature most frequently identified as contributing to its usefulness as an instructional strategy was the visual quality of the mapping task. Constructing a visual representation provided students with a different method for organizing their ideas. Interestingly, many students identified themselves as having a visual learning preference. Recent research finds little evidence to support the idea that tailoring instruction to different learning style preferences makes a difference in student learning outcomes (Rohrer \& Pashler, 2012). Findings from this study suggests there may be some value in students identifying themselves as having a preferred learning style as it relates to using and seeing the learning benefits of specific teaching strategies. Additionally, the study illustrates how employing innovative pedagogies can present students with new experiences that may lead to deeper learning.

An additional feature of the activity that may have contributed to students' positive perceptions is the flexibility students had in designing their maps. The variety of the designs indicates that students used the freedom to create maps specific to each group's ideas for how to best understand the problem. Providing students with choice and ownership of their learning is a student-centered approach that can increase levels 
of engagement and motivation (Wright, 2011) and promote creativity. The lack of uniformity and restrictions on how to draw mind maps was appropriate in this case because the purpose was for students to use the activity to foster the process of interdisciplinary integration; it was not used as a direct measure of learning. Building flexibility into the collaborative mapping assignment may have also served to accommodate students who are more comfortable using traditional structured learning strategies.

\section{Learning Outcomes}

The study's findings also provide insights about learning outcomes from the activity. Students indicated that the collaborative mapping exercise facilitated an understanding of interdisciplinary integration, primarily by making the connections between disciplinary insights visible. In addition to helping identify connections, students indicated that the collaborative maps helped the group generate interdisciplinary themes, perform integration, construct new understandings and develop solutions for the problem. A reason for why this method may facilitate the integrative process stems from its theoretical underpinnings, that knowledge is actively and socially constructed (Bruner, 1986; Vygotsky, 1978) and involves making links between concepts (Ausubel, 1968; Novak, 1990). Another factor that may have led to deeper learning is having students reflect on the experience (Kolb, 1984). Providing feedback about the strategy's effectiveness required students to engage in metacognition, to think about the experience and the learning outcomes.

Skill development is an additional learning outcome from the collaborative mapping exercise. The findings suggest that students developed a range of skills including holistic and creative thinking, critical thinking, problem-solving, and collaboration skills. Phrases students used to describe the cognitive skills developed include seeing "the big picture" and "pathways to new ideas," "thinking out of the box," and

Students indicated that the collaborative mapping exercise facilitated an understanding of interdisciplinary integration, primarily by making the connections between disciplinary insights visible.

coming up with "new solutions." Critical thinking, problem-solving and collaborative skills were developed by listening to their group members' ideas and engaging in perspective-taking-analyzing different disciplinary perspectives on the problem (Repko, 2012). Higher education is under increased pressure to provide evidence that students are graduating with the knowledge and skills required to be successful in today's global society (Oliveri \& Markle, 2017). Findings from this research illustrate how a teaching strategy can be used to increase learning and develop the skills that are in high demand.

\section{Suggestions for Improvement}

While students' positive perceptions of collaborative mapping provide support for its application in teaching interdisciplinary studies and its continued use in the course, the findings offer suggestions for improving its effectiveness in the 
classroom. First, provide students with an introduction to the mapping assignment that includes an explanation of the learning objectives and the theoretical underpinnings and potential benefits derived from engaging in the activity. Instructors often focus on explaining the "how." Findings from this study illustrate the importance of also communicating the "why." If students see the value and personal relevance in what they are being asked to do, they are more likely to be actively involved in the learning process (Jessup-Anger, 2011). Second, to reduce the level of confusion and unease some students experience, provide additional time for students to experiment with different map designs to find a method that accommodates a range of preferred learning strategies. Third, to help students generate themes and deepen their interdisciplinary understanding of the problem, build in additional opportunities for students to become familiar with interdisciplinary research. Implementing these changes may strengthen the essential features of collaborative learning-planning, process and results (Barkley et al., 2014).

\section{Limitations and Future Research}

Although new insights were gained from the current study, there are possible limitations to the research findings. The findings are specific to one instructor's experience with students in one course. Additional research is needed to confirm its effectiveness in facilitating interdisciplinary learning and its wider application across disciplines. Furthermore, because student evaluations were identifiable, knowing the instructor would read the comments may have influenced the statements provided. Other areas for future research include further investigation into factors that affect the effectiveness of interdisciplinary teams and designing studies that assess the effectiveness of teaching strategies by providing direct measures of interdisciplinary learning.

\section{Conclusion}

This research contributes new understandings about using student perceptions to assess the effectiveness of a teaching and learning strategy. It illustrates that student perceptions of their learning experiences matter. They matter because these perceptions can inform and improve teaching practice which may result in higher levels of active engagement and learning. Additionally, gaining students' perceptions can communicate to students that they have a voice and that instructors are responsive to their learning needs. This study also provides insights about how important it is to employ instructional strategies that are best suited to achieving specific learning goals. In this study, collaborative mapping was selected in part to encourage active engagement with the additional purpose of helping students integrate insights across disciplines, the primary cognitive task required for interdisciplinary learning. Finally, the findings demonstrate how teaching strategies should aim not only to increase knowledge, but to develop the personal, academic and professional skills needed today. Making changes to current practice requires time, effort and a strong commitment to continuous improvement-a commitment that may lead to improving teaching effectiveness in higher education. 


\section{References}

Allen, E. G. (2016). “I hate group work!”: Addressing students' concerns about small-group learning. InSight: A Journal of Scholarly Teaching, 11, 81-98.

Ausubel, D. P. (1968). Educational psychology: A cognitive view. New York, NY: Holt, Rinehart \& Winston.

Barkley, E. F., Cross K. P., \& Major, C. H. (2014). Collaborative learning techniques: A handbook for college faculty. Hoboken, NJ: John Wiley \& Sons.

Boix Mansilla, V. (2005). Assessing student work at disciplinary crossroads. Change, 37(1), 14-21.

Brassler, M., \& Dettmers, J. (2017). How to enhance interdisciplinary competence--interdisciplinary problembased learning versus interdisciplinary project-based learning. Interdisciplinary Journal of Problem-Based Learning, 11(2). https://doi.org/10.7771/1541-5015.1686

Bruner, J. S. (1986). Actual minds, possible worlds. Retrieved from https://ebookcentral.proquest.com

Buzan, T. (1994). The mind map book: How to use radiant thinking to maximize your brain's untapped potential. New York, NY: Dutton.

Carmichael, T., \& LaPierre, Y. (2014). Interdisciplinary learning works: The results of a comprehensive assessment of students and student learning outcomes in an integrative learning community. Issues in Interdisciplinary Studies, 32, 53-78.
Channon, S. B., Davis, R. C., Goode, N. T., \& May, S. A. (2017). What makes a "good group"? Exploring the characteristics and performance of undergraduate student groups. Advances in Health Sciences Education, 22(1), 17-41.

Chiou, C. C. (2008). The effect of concept mapping on students' learning achievements and interests. Innovations in Education and Teaching International, 45(4), 375-387.

Duffill, N. (2013). Choosing and using mind maps and concept maps. Retrieved from http://www.olympiclimited.co.uk/wpcontent/uploads/2013/05/Choosing-andusing-Mind-Maps-and-ConceptMaps.pdf

Everett, M. C. (2016). Interdisciplinary studies: A site for bridging the skills divide. Journal of Effective Teaching, 16(2), 20-31.

Haynes, C. (Ed.). (2002). Innovations in interdisciplinary teaching. Westport, CT: Oryx/Greenwood Press.

Hay, D., Kinchin, I., \& Lygo-Baker, S. (2008). Making learning visible: The role of concept mapping in higher education. Studies in Higher Education, 33(3), 295311.

Hay, D., Wells, H., \& Kinchin, I. (2008). Quantitative and qualitative measures of student learning at university level. Higher Education, 56, 221-239. 
Holley, K. A. (Ed.). (2009). Special issue: Understanding interdisciplinary challenges and opportunities in higher education. ASHE Higher Education Report, 35(2), 1-131.

Imafuku, R., Kataoka, R., Mayahara, M., \& Suzuki, H. (2014). Students' experiences in interdisciplinary problem-based learning: A discourse analysis of group interaction. Interdisciplinary Journal of Problem-Based Learning, 8(2), 1-19. doi: 10.7771/15415015.1388

Jessup-Anger, J. E. (2011). What's the point? An exploration of students' motivation to learn in a first-year seminar. The Journal of General Education, 60(2), 101-116.

Johnson, D. T., \& Johnson, R. T. (1999). Making cooperative learning work. Theory into Practice, 38(2), 67-73.

Klein, J. T. (2005). Integrative learning and interdisciplinary studies. Peer Review, 7(3/4), 8-10.

Kinchin, I., \& Hay, D. (2005). Using concept maps to optimize the composition of collaborative student groups: A pilot study. Journal of Advanced Nursing, 51(2), 182-187.

Kolb, D. A. (1984). Experiential learning: Experience as the source of learning and development. Englewood Cliffs, NJ: Prentice Hall.

Krometis, L. H., Clark E. P., Gonzalez, V., \& Leslie, M. E. (2011). The 'death' of disciplines: Development of a teamtaught course to provide an interdisciplinary perspective for firstyear students. College Teaching, 59(2), 7378.
Lattuca, L., Voigt, L., \& Fath, K. (2004). Does interdisciplinarity promote learning? Theoretical support and researchable questions. The Review of Higher Education, 28(1), 23-48.

Machemer, P. L., \& Crawford, P. (2007). Student perceptions of active learning in a large cross-disciplinary classroom. Active Leaning in Higher Education, 8(1), 11-31.

Mueller, A., Juris, S. J., Willermet, C., Drake, E., Upadhaya, S., \& Chhetri, P. (2014). Assessing interdisciplinary learning and student activism in a water issues course. Journal of The Scholarship of Teaching \& Learning, 14(2), 111-132.

National Association of Colleges and Employers. (2018). The key attributes employers seek on students' resumes [Press release]. Retrieved from http://www.naceweb.org/aboutus/press/2017/the-key-attributesemployers-seek-on-students-resumes/

Newell, W. H. (2001). A theory of interdisciplinary studies. Issues in Integrative Studies, 19, 1-25.

Ng, B. L., Yap, K. C., \& Hoh, Y. K. (2011). Students' perception of interdisciplinary, problem-based learning in a food biotechnology course. Journal of Food Science Education, 10(1), 48 .

Novak, J. D. (1990). Concept maps and vee diagrams: Two metacognitive tools to facilitate meaningful learning. Instructional Science, 19(1), 29-52. 
Novak, J. D., \& Cañas, A. J. (2008). The theory underlying concept maps and how to construct and use them. [Technical report]. Retrieved from: http://cmap.ihmc.us/publications/resear chpapers/theorycmaps/theoryunderlyin gconceptmaps.htm

Oliveri, M. E., \& Markle, R. (2017). Continuing a culture of evidence: Expanding skills in higher education. ETS Research Report Series.

Patton, M. Q. (2002). Qualitative research and evaluation methods ( $3^{\text {rd }}$ ed.). Thousand Oaks, CA: Sage Publishing.

Powell, K. C., \& Kalina, C. J. (2009). Cognitive and social constructivism: Developing tools for an effective classroom. Education, 130(2), 241-250.

Quinn, H. J., Mintzes, J. J., \& Laws, R. A. (2003). Successive concept mapping: Assessing understanding in college science classes. Journal of College Science Teaching, 33(3) 12-16.

Repko, A. F. (2012). Interdisciplinary Research: Process and Theory ( $2^{\text {nd }}$ ed.). Thousand Oaks, CA: Sage Publishing.
Repko, A. F., Szostak, R., \& Buchberger M. P. (2017). Introduction to interdisciplinary studies (2 ${ }^{\text {nd }}$ ed.). Thousand Oaks, CA: Sage Publishing.

Rohrer, D. \& Pashler, H. (2012). Learning styles: Where's the evidence? Medical Education, 46(7), 634-635. doi: 10.1111/j.1365-2923.2012.04273.x

Stentoft, D. (2017). From saying to doing interdisciplinary learning: Is problembased learning the answer? Active Learning in Higher Education, 18(1), 51-61.

Szostak, R. (2007). How and why to teach interdisciplinary research practice. Journal of Research Practice, 3(2), 1-16.

You, H. S., Marshall, J. A., \& Delgado, C. (2018). Assessing students' disciplinary and interdisciplinary understanding of global carbon cycling. Journal of Research in Science Teaching, 55(3). 377. doi: 10.1002/tea.21423

Vygotsky, L. (1978). Mind in Society. London: Harvard University Press.

Wright, G. B. (2011). Student-centered learning in higher education. International Journal of Teaching and Learning in Higher Education, 23(3), 92-97.

Michele C. Everett, formerly a Lecturer of Interdisciplinary Studies at Coastal Carolina University, has been teaching and coordinating the first-year experience and peer mentor programs. Her research focuses on teaching and learning in higher education with specific interest in strategies for student engagement, well-being, and interdisciplinary ways of knowing. 